\title{
8
}
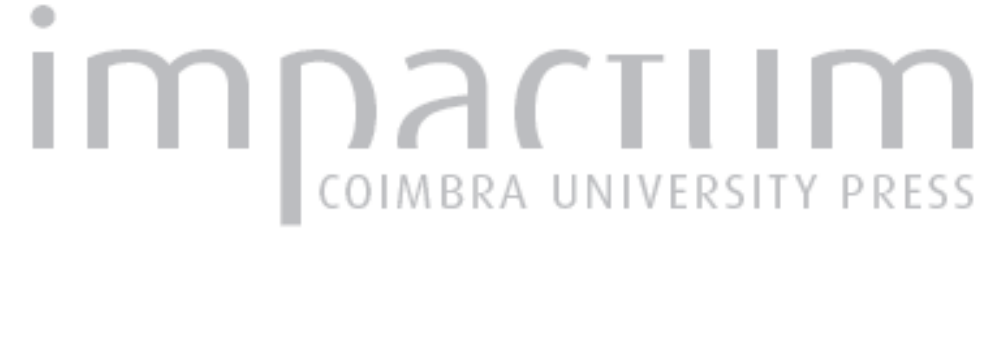

\section{A refutação dos argumentos ontológico, cosmológico e físico-teológico na crítica da razão pura em Immanuel Kanti}

Autor(es): $\quad$ Mulinari, Filício

Publicado por: Universidade Católica de Petrópolis; Instituto Brasileiro de Informação

em Ciência e Tecnologia

URL

persistente:

URl:http://hdl.handle.net/10316.2/33047

DOI:

DOI:http://dx.doi.org/10.14195/1984-6754_3-1_2

Accessed : $\quad$ 26-Apr-2023 15:58:01

A navegação consulta e descarregamento dos títulos inseridos nas Bibliotecas Digitais UC Digitalis, UC Pombalina e UC Impactum, pressupõem a aceitação plena e sem reservas dos Termos e Condições de Uso destas Bibliotecas Digitais, disponíveis em https://digitalis.uc.pt/pt-pt/termos.

Conforme exposto nos referidos Termos e Condições de Uso, o descarregamento de títulos de acesso restrito requer uma licença válida de autorização devendo o utilizador aceder ao(s) documento(s) a partir de um endereço de IP da instituição detentora da supramencionada licença.

Ao utilizador é apenas permitido o descarregamento para uso pessoal, pelo que o emprego do(s) título(s) descarregado(s) para outro fim, designadamente comercial, carece de autorização do respetivo autor ou editor da obra.

Na medida em que todas as obras da UC Digitalis se encontram protegidas pelo Código do Direito de Autor e Direitos Conexos e demais legislação aplicável, toda a cópia, parcial ou total, deste documento, nos casos em que é legalmente admitida, deverá conter ou fazer-se acompanhar por este aviso. 

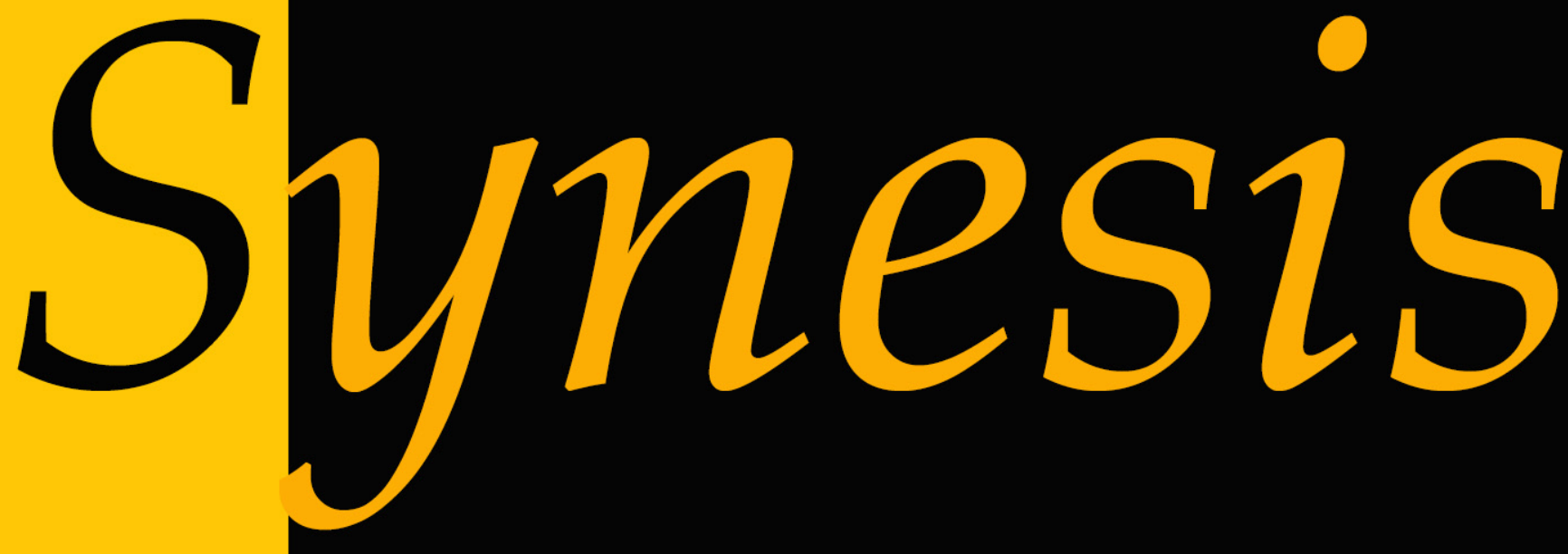

Revista do Centro de Teologia e Humanidades ISSN 1984-6754

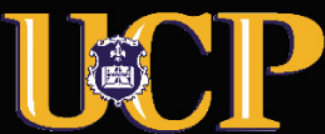




\section{A REFUTAÇÄO DOS ARGUMENTOS ONTOLÓGICO, COSMOLÓGICO E FÍSICO-TEOLÓGICO NA CRÍTICA DA RAZÁO PURA DE IMMANUEL KANT}

Filício Mulinari ${ }^{2}$

Resumo: O objetivo deste artigo é analisar a refutação proposta por Immanuel Kant (17241804) em sua obra Crítica da Razão Pura ([1781] 2001) aos argumentos clássicos que almejavam provar a existência de Deus presentes na história da filosofia. De acordo com a ordem de refutação feita na Crítica da Razão Pura, será analisada primeiramente a refutação kantiana do argumento ontológico, que é fundamentado na definição do Ente perfeito (ens perfectissimum). Após isso, será analisada a contestação de Kant aos argumentos tidos como "cosmológicos", argumentos estes fundamentados no princípio de causalidade. Por fim, será analisada a refutaçáo kantiana aos argumentos físico-teológicos.

Palavras-Chave: Metafísica moderna; ontologia; ser; existência; argumento ontológico

Abstract: The aim of this paper is to analyze the refutation proposed for Immanuel Kant (17241804) in his work Critique of Pure Reason ([1781] 2001) to the classical arguments for the existence of God presents in history of philosophy. According to the order of Kant's refutation made in Critique of Pure Reason, will be examined firstly the Kantian refutation of ontological argument, which is based on the definition of ens perfectissimum. After this, will be examined the Kant's contestation to the 'cosmological arguments', these arguments based on the principle of causality. Finally, will be analyzed the Kantian refutation of the physico-theological arguments.

Keywords: Modern metaphysic; ontology; being; existence; ontological argument

\footnotetext{
${ }^{1}$ Artigo recebido em 27/02/2011 e aprovado para publicação pelo Conselho Editorial em 29/05/2011.

2 Aluno bolsista CAPES do Programa de Pós Graduação em Filosofia da Universidade Federal do Espírito Santo (UFES). Currículo Lattes: http://lattes.cnpq.br/2163193321069411. Email: filicio@gmail.com. 


\section{Introduçáo}

O problema em torno da existência de um Ser Supremo (Deus) sempre esteve presente na história da filosofia ocidental, seja no campo da metafísica, seja - mais modernamente - no campo da filosofia da religião. Desde Platão (Leis, Livro X, caps. 2-9) e Aristóteles (Metafísica, livro XII, caps. 6-7), vários pensadores tentaram, racionalmente, elucidar o que seria este Ente e provar sua possível existência. Embora a meditaçáo sobre Deus seja táo antiga quanto à própria filosofia, os avanços da ciência moderna alçaram novos desafios a esta área tradicional da reflexão filosófica.

Em meio ao debate filosófico em torno da existência de Deus, o filósofo alemáo Immanuel Kant (1724-1804) figura como personagem de grande importância, principalmente devido a sua obra Crítica da Razão Pura ([1781] 2001). Na obra, Kant definiu a noção de existência (ser) como não sendo predicado determinante de alguma coisa e, fundamentado nisso, refutou os clássicos argumentos que tentavam provar a existência de Deus presentes até então na história da filosofia. Os mais tradicionais argumentos em prol da existência de Deus presentes na filosofia, os chamados 'argumentos ontológicos', ${ }^{3}$ haviam sido elaborados por Santo Anselmo (1033-1109) e Descartes (1596-1650) e a refutação desses argumentos é um dos principais resultados alcançados pela filosofia crítica de Kant. ${ }^{4}$

A crítica desferida por Kant contra aos argumentos ontológicos é direcionada à pretensão de tornar aquilo que é apenas um juízo lógico em uma afirmação de existência. ${ }^{5}$ Segundo a tese de Kant, para que um juízo afirme a existência de algo ele deve ser sintético, ou seja, deve unir o sujeito a um predicado não meramente lógico, mas real.

3 O argumento ontológico é chamado assim porque pretende tirar a existência da essência: não posso pensar um ser absolutamente necessário sem pensá-lo ao mesmo tempo como existente, posto que um ser necessário é, por definição, um ser cuja não-existência é impossível (PASCAL, 1983, p.100-101).

4 Apesar de ser um dos principais resultados alcançados pela filosofia crítica de Kant, salienta-se que a refutação dos argumentos ontológicos já estava presente também - de modo similar - no período pré-crítico, no Beweisgrund.

5 Anselmo de Aosta, no seu Proslogion, proporciona uma demonstração da existência de Deus com argumento que Kant chamda de ontológico, uma vez que deduz a existência de Deus de seu puro existir, a priori, tornando-se na história da filosofia algo abstraído do contexto de fé no qual era proposto, ou seja, tornando-se um argumento simplesmente lógico (TOMATIS, 2003, p. 16). 
Nesse sentido, o objetivo deste artigo é analisar a refutação kantiana presente na obra Crítica da Razão Pura ([1781] 2001) aos argumentos clássicos presentes na história da filosofia que almejavam provar a existência de Deus. De acordo com a ordem de refutação feita na Crítica da Razáo Pura, será analisada primeiramente a refutação kantiana do argumento ontológico, que é fundamentado na definição do Ente Perfeito (ens perfectissimum). Após isso, será analisada a contestação de Kant aos argumentos tidos como "cosmológicos", argumentos estes fundamentados no princípio de causalidade. Por fim, será analisada a refutação kantiana aos argumentos físico-teológicos, último tipo de argumento analisado e refutado por Kant na Crítica da Razão Pura.

\section{A crítica kantiana ao argumento ontológico}

Na Crítica da Razão Pura, no capítulo sobre "O ideal da razão Pura" da Dialética Transcendental, Kant retomou substancialmente a problemática das provas da existência de Deus, principalmente o argumento ontológico de Descartes, e propôs uma análise que refuta tais provas. Na quarta seção do capítulo "O Ideal da razão pura", intitulado Da impossibilidade de uma prova ontológica da existência de Deus, ${ }^{6}$ Kant proferiu as seguintes palavras:

Em todos os tempos se falou do ser absolutamente necessário, mas envidaram-se mais esforços para provar a sua existência do que para compreender como se poderá e até mesmo se se poderá pensar uma coisa desta espécie. Ora, é muito fácil dar uma definição nominal do que seja este conceito, dizendo que é algo cuja não-existência é impossível; mas nem por isso ficamos mais cientes das condiçóes que tornam impossível considerar a não-existência de uma coisa como absolutamente impensável e que são, na verdade, aquilo que se pretende saber, isto é, se através desse conceito pensamos ou não em geral qualquer coisa (KANT, 2001, A592-593/B620-621).

Desse modo, percebe-se a pretensão de Kant em avaliar se as provas da existência de Deus são, de fato, provas fundamentadas. Para isso Kant inicialmente analisou o argumento ontológico, principalmente o proposto por Descartes, que toma Deus como ente perfeito e necessário.

$6 \quad$ KANT, 2001, A592/B620. 
Em Descartes, a idéia de Deus como ser perfeito é expressa juntamente com a idéia de infinito. Descartes alegou que, para que exista uma causa da idéia de Deus no homem, é necessário que tal causa seja maior do que o próprio efeito. O pressuposto de Descartes é que para que algo seja causado, a sua causa deve ser maior do que o efeito, ou entáo não poderia causá-lo. De acordo com Tomatis (2003, p.46), "este pressuposto Descartes retira da tradiçáo especulativa precedente: na causa deve-se encontrar pelo menos a mesma realidade que se encontra no efeito causado".

Pois, como já disse anteriormente, é uma coisas evidente que deve haver ao menos tanta realidade na causa quanto em seus efeito. E portanto, já que sou uma coisa pensante, e tenho em mim alguma idéia de Deus, qualquer que seja, enfim, a causa que se atribua à minha natureza, cumpre necessariamente confessar que ela deve ser de igual modo uma coisa pensante e possuir em si a idéia de toas as perfeiçóes que atribuo à natureza divina (DESCARTES, 1983, p. 119).

Logo, para Descartes a partir da idéia de Deus presente na mente do homem necessariamente deve-se deduzir a existência de Deus, uma vez que "Deus é aquele ser perfeitíssimo que causa a nossa idéia, que temos em mente e, portanto, deve ser necessariamente existente". A prova ontológica reside então em afirmar a verdadeiramente a existência de Deus a partir de seu mero conceito, juntamente com o conceito de infinito e, a partir disso, assumir a necessidade de sua existência a partir da mera análise de conceitos, sem nenhuma inferência ou evidência empírica.

Kant foi contrário a posição cartesiana na qual a existência faria parte da perfeição de Deus. Para Kant, a existência nada acrescenta ao conceito de Deus, mesmo que tal conceito seja tomado como ente perfeito:

Ser não é, evidentemente, um predicado real, isto é, um conceito de algo que possa acrescentar-se ao conceito de uma coisa; é apenas a posiçấo de uma coisa ou de certas determinações em si mesmas. No uso lógico é simplesmente a cópula de um juízo. A proposição Deus é omnipotente contém dois conceitos que têm os seus objetos: Deus e onipotência; a minúscula palavra é não é um predicado mais, mas tão-somente o que pôe o predicado em relação com o sujeito. Se tomar pois o sujeito (Deus) juntamente com todos os seus predicados (entre os quais se conta também a onipotência) e disser Deus é, ou existe um Deus, não acrescento um novo predicado ao conceito de Deus, mas apenas ponho o sujeito em si mesmo, com todos os seus predicados e, ao mesmo 
tempo, objeto que corresponde ao meu conceito. Ambos têm de conter, exatamente. o mesmo; e, em virtude de eu pensar o objeto desse conceito como dado em absoluto (mediante a expressão: ele é), nada se pode acrescentar ao conceito, que apenas exprime a sua possibilidade. E assim o real nada mais contém que o simplesmente possível (KANT, 2001, p. 626).

Como salienta Tomatis (2003, p. 79), em uma proposição que expressa um juízo, composta por sujeito, verbo e predicado, e no qual o verbo ser seja uma cópula, percebe-se que através do próprio verbo ser náo podemos concluir a existência do sujeito: a existência nada acrescenta ao sujeito da proposição. Como fica claro na citação acima, a existência para Kant seria apenas o posicionamento absoluto de uma coisa.

Se para Descartes seria possível inferir a existência de Deus através análise lógica dos predicados pertencentes ao próprio termo 'Deus', para Kant isto não seria possível. Em outras palavras, para Kant a existência náo poderia ser deduzida dos predicados e/ou qualidades que pertencem ao conceito Deus:

A existência não pode ser predicada. Dizendo "Deus é uma coisa existente" pensa-se expressar a relaçáo de um predicado com um sujeito; na realidade existe uma inexatidão nesta expressão. Seria melhor dizer: "Alguma coisa de existente é Deus". O sujeito é "alguma coisa de existente", "Deus" é o predicado. A uma coisa existente dizem respeito predicados que tomados em conjunto são contrapostos com a expressão "Deus" (TOMATIS, 2003, p.80).

Segundo Kant, a existência seria algo posterior ao predicado e que não modifica em nada a definição do predicado, da substância, do sujeito do qual se afirma a existência. Sobre esta tese, Kant proporcionou o clássico exemplo dos "cem táleres" como referência:

E assim o real nada mais contém que o simplesmente possível. Cem talheres reais não contêm mais do que cem talheres possíveis. Pois que se os talheres possíveis significam o conceito e os talheres reais o objeto e a sua posição em si mesma, se este contivesse mais do que aquele, o meu conceito não exprimiria o objeto inteiro e não seria, portanto, o seu conceito adequado. Mas, para o estado das minhas posses, há mais em cem talheres reais do que no seu simples conceito (isto é na sua possibilidade). Porque, na realidade, o objeto não está meramente contido, analiticamente, no meu conceito, mas é sinteticamente acrescentado ao meu conceito (que é uma determinação

Táler é o nome da antiga moeda alemã.

http://seer.ucp.br/seer/index.php/synesis/index 
do meu estado), sem que por essa existência exterior ao meu conceito os cem talheres pensados sofram o mínimo aumento (KANT, 2001, A599/B627).

Com a citação acima, percebe-se que a existência não acrescenta em nada à definição das cem moedas: as moedas que estavam no pensamento são as mesmas que estão no agora no bolso. Certamente a existência das moedas é algo posterior à idéia, no entanto isto não afeta em nada a definição lógica (definição ideal) que se tem dessas moedas.

Dessa forma, salienta-se que o argumento ontológico é rejeitado de dois modos distintos, embora associados: um diz respeito à lógica, e outro à relação entre pensamento e o mundo (ontologia). ${ }^{8}$ Primeiramente, o argumento ontológico é refutado por que a afirmação da existência de algo não pode ser derivada da simples análise de outros conceitos. Em segundo lugar, a rejeição do argumento ontológico é feita devido à confusão entre o aspecto material e o aspecto formal da possibilidade presente no argumento, uma vez que da mera náo-contradição conceitual de Deus (aspecto formal) não se deduz a existência do mesmo.

A base da refutação kantiana aos argumentos ontológicos já estava presente em um escrito anterior intitulado Beweisgrund, de $1763 .^{9}$ A diferença entre o texto pré-crítico e a Crítica da Razão Pura fica por conta da análise dos argumentos da existência de Deus classificados como cosmológico e físico-teológico. A refutação a estes argumentos aparece de modo mais distinto no período crítico.

\section{A refutação do argumento cosmológico}

Decerto, o método usado no argumento ontológico não é o único existente na história da filosofia que pretende provar a existência de Deus. Há outros métodos que possuem essa mesma pretensão, mas que usam de outro tipo de argumentação para provar a existência de Deus, não sendo da análise lógica para a afirmação de existência (como no argumento ontológico). Após criticar o argumento ontológico cartesiano, Kant criticou esses outros tipos de argumentos,

VAZ, 2006, p. 69.

Título original: Der einzig mögliche Beweisgrund zu einer Demostration des Daseins Gottes. http://seer.ucp.br/seer/index.php/synesis/index 
classificando-os em dois tipos, a saber, os cosmológicos e os físico-teológicos. Kant mostrou a falta de fundamento desses argumentos e, em última instância, que tanto o cosmológico quanto o físico-teológico são provas que possuem o argumento ontológico como fundamento.

Na quinta seção do capítulo "O Ideal da Razão Pura", Kant iniciou sua argumentação contra os argumentos classificados como cosmológicos:

A prova cosmológica, que vamos agora examinar, mantém a ligação da necessidade absoluta com a realidade suprema; mas, em vez de partir, como a precedente, da realidade suprema, para deduzir a necessidade na existência, conclui da necessidade incondicionada e previamente dada, de qualquer ser, a sua realidade ilimitada e, deste modo, tudo encaminha por um raciocínio, não sei se racional se sofístico, mas que é, pelo menos, natural e que possui a maior força persuasiva, não só para o entendimento comum, mas também para o entendimento especulativo; e desta maneira traça visivelmente as primeiras linhas diretrizes de todos os argumentos da teologia natural, linhas que sempre foram seguidas e hão de sê-lo sempre, por muito que se adornem e disfarcem sob floreados e arrebiques (KANT, 2001, A604/B632).

Entende-se prova cosmológica da existência de Deus como o argumento que parte de uma existência qualquer e, ao usar o princípio de causalidade, afirma que se tudo tem uma causa, deve haver uma causa primeira motora de tudo e que, por sua vez, é imóvel: tal causa primeira seria Deus.

Como foi citado anteriormente, um exemplo desse tipo de argumentação é proposto por Aristóteles para deduzir a existência de um "primeiro motor imóvel". ${ }^{10}$ Porém, conforme salienta Reichenbach (2008), é importante frisar que o argumento cosmológico é um tipo de argumentação, e não um argumento particular.

O argumento cosmológico é um tipo de argumentação (logos) que infere de determinados fatos do o mundo (cosmos) à existência de um único ser, geralmente identificado ou referido como Deus. Dentre estes fatos iniciais, estão que o mundo veio a ser, que o mundo é contingente e que poderia ter sido outra que isto e que certos seres ou eventos no mundo são causadamente dependentes ou contingentes. Desses fatos, filósofos inferiam também, dedutivamente ou indutivamente, que uma causa

10 Para provar a existência de Deus, Aristóteles supõe, em sua obra Metafísica (livro XII, caps. 6-7), que tempo e movimento tenham um começo. Para explicar a existência do tempo e do movimento, é preciso postular uma causa primeira que, em si mesma, não se move. Esta causa é denominada de primeiro motor, uma espécie de mente que está sempre pensando e que age sobre as esferas celestes (SMITH, 2006, p.10). 
primeira, um ser necessário, um motor imóvel ou Deus deve existir (REINCHENBACH, 2008, p. 1). ${ }^{11}$

Observa-se que o argumento central da prova cosmológica repousa na aceitação de que se algo existe, um ser absolutamente necessário (Deus) deve existir. Por ser muito conhecida, Kant não aprofundou demasiadamente as implicaçôes e argumentações internas existentes nas provas cosmológicas. No entanto, vê-se em uma nota de rodapé a concepção kantiana do princípio desta prova:

Esta argumentação [argumentação da prova cosmológica] é demasiado conhecida para ser necessário expô-la neste lugar, pormenorizadamente. Repousa na lei natural, suposta transcendental, da causalidade, a saber, que todo o contingente possui uma causa, que, se por sua vez é contingente, deve também ter uma causa, até que a série das causas subordinadas pare numa causa absolutamente necessária, sem a qual não seria jamais completa (KANT, 2001, A605/B633).

Conforme a argumentação da prova cosmológica, tudo que existe de modo contingente deve necessariamente ter uma causa que, se é por sua vez contingente ad infinitum até que a série das causas contingentes termine em uma causa absolutamente necessária. Conforme salienta Höffe (2005, p.170-171), sem uma causa absolutamente necessária e, portanto, sem necessidade de explicação, não teríamos uma explicação completa nem poderíamos fundamentar suficientemente o contingente na sua existência efetiva. Desse modo, há na argumentação cosmológica, baseada no princípio da causalidade, a afirmação da existência de algo necessário que se apresenta como ente perfeito.

Contudo está, na prova cosmológica, "oculto todo um ninho de pretensóes dialéticas": ${ }^{12}$

1. O princípio transcendental que do contingente nos faz inferir uma causa, princípio que só tem significado no mundo sensível, mas que já não tem sentido fora desse mundo. Com efeito, o conceito puramente intelectual do contingente náo pode produzir nenhuma proposição sintética como a da causalidade, e o princípio desta só no mundo sensível encontra significação e critério para a sua aplicação; aqui, porém, deveria precisamente servir para sair do mundo sensível. 2. O raciocínio que consiste em concluir, da impossibilidade de uma série infinita de causas sobrepostas dadas no

11

It uses a general pattern of argumentation (logos) that makes an inference from certain alleged facts about the world (cosmos) to the existence of a unique being, generally identified with or referred to as God. Among these initial facts are that the world came into being, that the world is contingent in that it could have been other than it is, or that certain beings or events in the world are causally dependent or contingent. From these facts philosophers infer either deductively or inductively that a first cause, a necessary being, an unmoved mover, or a personal being (God) exists (REINCHENBACH, 2008, p. 1).

$12 \quad$ KANT, 2001, A609/B637. 
mundo sensível, uma causa primeira; $o$ que nem os princípios do uso da razão autorizam na própria experiência, quanto mais tornar extensivo este princípio para além dela (até onde esta cadeia não pode prolongar-se) (KANT, 2001, A610/B638).

Conforme salientado na passagem citada acima, percebe-se que o princípio de causalidade - princípio transcendental que permite inferir do contingente uma causa necessária - só possui validade de aplicação no mundo sensível, mas não fora ou para além dele. Segundo Kant, o princípio da causalidade só encontra sentido no mundo sensível, pois há no mundo sensível critérios para sua aplicação e verificação. Dessa forma, um dos erros fundamentais da prova cosmológica é o de querer aplicar a categoria da causalidade fora do mundo da experiência e, com isso, inferir a existência de algo, o que seria impossível para Kant.

O princípio, pelo qual, do que acontece (do que é empiricamente contingente) como efeito se conclui uma causa, é um princípio do conhecimento da natureza, mas não do conhecimento especulativo (KANT, 2001, A635/B663).

Há ainda outra questão salientada por Kant: por que parar o questionamento da causa quando se chega ao conceito de Deus? Por que não se pode perguntar pela causa de Deus?

\begin{abstract}
Não podemos afastar nem tão-pouco suportar o pensamento de que um ser, que representamos como o mais alto entre todos os possíveis, diga de certo modo para consigo: Eu sou desde a eternidade para a eternidade; fora de mim nada existe a não ser pela minha vontade; mas de onde sou então? Eis que tudo aqui se afunda sob os nossos pés, e tanto a maior como a mais pequena perfeição pairam desamparadas perante a nossa razão especulativa, à qual nada custa fazer desaparecer uma e outra sem o menor entrave (KANT, 2001, A613/B641).
\end{abstract}

Percebe-se que a certeza sobre o ens necessarium advindo da prova cosmológica tem suas bases enfraquecidas com estes questionamentos. Em outras palavras, com o questionamento a respeito da causa que originou Deus, abre-se novamente a possibilidade da pergunta sobre a causa ad infinitum. Conseqüentemente, a representaçáo cosmológica da existência de Deus não cumpre o seu objetivo, que é "[...] encontrar uma resposta definitiva a toda interrogação da causalidade, isto é, um suporte último de todo o ser. A razão impele para a conclusão do perguntar, mas não pode encontrar um fim definitivo" (HÖFFE, 2005, 171).

Contudo, Kant viu em outra objeção o contra-argumento mais importante. ${ }^{13}$ Segundo a argumentação cosmológica, só há demonstração ou "prova" de Deus quando se infere do

13 HÖFFE, 2005, p. 171.

http://seer.ucp.br/seer/index.php/synesis/index 
conceito do ser absolutamente necessário a existência de Deus. Aqui, assim como no argumento ontológico de Descartes, não se usa a experiência para inferir a existência de Deus: a mera análise de conceitos lógicos se presume a existência do ens realissimum.

O fundamento empírico da prova nada nos pode ensinar acerca dos atributos deste ser; então a razão afasta-se dele inteiramente e, por detrás de simples conceitos, investiga os atributos I que um ser absolutamente necessário em geral deve possuir; ou seja, um ser que, entre todas as coisas possíveis, encerra as condiçốes requeridas (requisita) para uma necessidade absoluta. [...]Eis uma proposição, sustentada pelo argumento ontológico, que assim se admite e se dá por fundamento ao argumento cosmológico, o que afinal se pretendera evitar [KANT, 2001 A607 B635].

$\mathrm{O}$ argumento cosmológico necessita em seu fundamento do argumento ontológico na medida em que o último infere a existência a partir de meros conceitos lógicos. Entretanto, como foi anteriormente visto, não é possível inferir a existência de a partir da mera análise de conceitos, sem nenhum apoio da experiência sensível. A necessidade da prova ontológica invalidaria a conclusão da argumentaçáo da prova cosmológica. Logo, conclui-se que mesmo sendo iniciado com premissas provindas da experiência (principio da causalidade), o argumento cosmológico possui, em seu fundamento, o argumento ontológico, que foi anteriormente criticado e refutado por Kant e que impossibilitaria a conclusão de que Deus é in re.

\section{A crítica ao argumento físico-teológico}

Após refutar as provas ontológicas e cosmológicas da existência de Deus, ainda resta uma a ser refutada por Kant, que é a prova físico-teológica. Tal refutação é feita na sexta seção do capítulo "O Ideal da Razáo Pura":

Se, portanto, nem o conceito das coisas em geral nem a experiência de qualquer existência em geral podem conceder o que é requerido, só resta um meio: procurar se uma experiência determinada, por conseguinte a das coisas do mundo presente, se a sua natureza e ordenação, não fornecem um fundamento de prova que nos possa fazer chegar, com segurança, à convicção da existência de um Ser supremo. A uma tal prova daríamos o nome de físico-teológica. Se também esta prova for impossível, não haverá, extraída da razão simplesmente especulativa, nenhuma prova suficiente da existência de um ser que corresponda à nossa idéia transcendental (KANT, 2001, A620/B648). 
A prova físico-teológica caracteriza-se por se iniciar da consideração da ordem universal da natureza física, para chegar a uma causa inteligente organizadora, considerada como extrínseca ao mundo e divina. ${ }^{14}$

Como salienta Höffe (2005, p. 172), há três momentos de argumentação na prova físicoteológica: primeiro infere-se um autor da ordem e da finalidade da natureza; após isso, infere-se uma plenitude absoluta da ordem e da finalidade natureza, que corresponde a um autor absolutamente necessário e; por fim, do autor absolutamente necessário conclui-se a existência de Deus (como autor necessário).

Por toda a parte vemos uma cadeia de efeitos e de causas, de fins e de meios, uma regularidade na aparição e desaparição das coisas e, visto que nada chega, por si mesmo, ao estado em que se encontra, este estado aponta sempre para mais além, para uma outra coisa como sua causa, a qual, por sua vez, exige que se prossiga a interrogaçáo; de tal sorte que tudo acabaria por afundar-se no nada se náo se admitisse alguma coisa que, existindo por si, originariamente e de uma maneira independente, fora desta contingência infinita, servisse de suporte a esse todo e que, sendo a sua origem, lhe garantisse ao mesmo tempo a duraçáo. Esta causa suprema (em relação a todas as coisas do mundo), com que grandeza a devemos conceber? (KANT, 2001, A622/B650).

Dessa forma, a prova físico-teológica parte da constituição particular do mundo, especificamente a sua beleza, ordem e intencionalidade, e afirma a necessária existência de uma causa inteligente (Deus). Tal argumento vai além da prova cosmológica pois inicia-se não a partir da existência em geral, mas a partir de uma experiência determinada, a fim de demonstrar a existência de Deus. ${ }^{15}$ Contudo, embora esta escolha por uma experiência determinada pareça tornar a argumentação mais sólida, tal estratégia está, segundo Kant, fadada ao fracasso, pois nenhuma experiência poderia ser adequada à idéia de um ser necessário:

A idéia transcendental de um ser originário necessário e absolutamente suficiente é tão hiperbolicamente grande, táo elevada acima do que é empírico e sempre condicionado, que, por um lado, não só não poderá nunca encontrar na experiência matéria suficiente para preencher tal conceito, mas também, por outro lado, sempre se anda às apalpadelas entre o condicionado e sempre se procura em vão o incondicionado, do qual nenhuma lei de síntese empírica nos dará jamais um exemplo, nem o menor indício (KANT, 2001, A621/B649).

14 TOMATIS, 2003, p. 87.

GRIER, 2007, p. 19. 
Percebe-se, ainda, que na argumentação da prova físico-teológica há uma pretensa suposição de igualdade entre relaçóes naturais com os objetos feitos pelos homens (provindos da arte humana):

\begin{abstract}
Sem entrarmos aqui em disputa com a razão natural acerca do raciocínio pelo qual, a partir da analogia entre algumas produçóes da natureza e aquilo que a arte humana produz quando faz violência à natureza e a obriga a curvar-se aos nossos fins em vez de proceder segundo os seus (da semelhança dessas produçóes com casas, barcos, relógios), a razão conclui que a natureza deve ter precisamente por princípio uma causalidade do mesmo gênero, a saber, uma inteligência e uma vontade, fazendo derivar ainda de uma outra arte, embora de uma arte sobre-humana, a possibilidade interna da natureza livremente operante (KANT, 2001, A626/B653).
\end{abstract}

Kant salientou que é ilegítima a comparação entre relaçóes naturais com os produtos provindos da arte humana (barcos, relógios...): quando alguém vê um barco atracado na praia, ele claramente deduz que o barco náo foi criado sozinho, ou seja, alguém criou o barco e o deixou atracado ali (houve um criador). Porém, segundo Kant, é um erro utilizar desse tipo de argumentação para inferir que há um criador da natureza, visto a sua perfeição e beleza. Como salienta Höffe (2005, p.173), nesta pressuposiçáo se conclui ilegitimamente do conhecido o desconhecido.

Não obstante, a arte humana, quando opera, opera com um material já dado: não há a possibilidade de criação de um material originário. Assim, se há um 'organizador' do kosmos, tal organizador opera com os materiais que lhe são disponíveis. Logo, Kant conclui: "Esta prova poderia, quando muito, demonstrar um arquiteto do mundo, sempre muito limitado pela aptidâo da matéria com que trabalha, mas não um criador do mundo"(KANT, 2001, A627/B655).

O segundo momento da prova físico-teológica, que consiste em inferir um autor necessário da ordem e finalidade da natureza, para Kant corresponde diretamente à prova cosmológica anteriormente refutada.

Depois de se ter chegado a admirar a grandeza, a sabedoria, a potência, etc. do autor do mundo, não se podendo ir mais além, abandona-se uma vez por todas este argumento, assente em provas empíricas, e passa-se para a contingência do mundo que, desde o início, igualmente se inferira a partir da sua ordem e finalidade. Unicamente se transita então desta contingência, graças apenas a conceitos transcendentais, para a existência de um ser absolutamente necessário, e do conceito de necessidade absoluta da causa primeira para o conceito universalmente determinado ou determinante da mesma existência, ou seja, o de uma realidade que tudo compreende. Assim, travada na sua http://seer.ucp.br/seer/index.php/synesis/index 
empresa, a prova físico-teológica, neste embaraço, saltou subitamente para a prova cosmológica; e, como esta é tão-só uma prova ontológica disfarçada, o seu propósito realizou-se unicamente mediante a razão pura, embora de início tivesse renegado todo o parentesco com ela e submetido tudo a provas evidentes extraídas da experiência (KANT, 2001, A629/B657).

Kant advertiu que toda a experiência, até mesmo a experiência da beleza e da ordem da natureza, é limitada ao finito e ao condicionado. Náo se pode, a partir de uma experiência condicionada (limitada) sobre a natureza, inferir a existência de algo incondicionado por meio de um raciocínio apenas logicamente exposto e não observável. Em outras palavras, devem-se buscar causas naturais e observáveis para as experiências empíricas. Desse modo, o erro da prova físicoteológica reside na tentativa de se compensar a insuficiência empírica com razóes não-empíricas, ou seja: se há a natureza ordenada (experiência condicionada), deve-se haver um criador e ordenador dessa ordenação (experiência incondicionada).

Percebe-se, então, que a deduçáo do argumento de que há um ens realissimum, só é obtida por se mover longe de qualquer consideração do mundo empírico. Em outras palavras, Kant relata que aqui também o argumento é confiado a um argumento transcendental (a priori). ${ }^{16} \mathrm{De}$ fato, de acordo com Kant, a prova físico-teológica nunca poderia, dado o seu ponto de partida empírico, estabelecer a existência de Deus por ela mesma e, por este motivo, deve contar com o argumento ontológico em fases cruciais da argumentação.

Afirmo, por conseguinte, que esta prova físico-teológica nunca pode, por si só,
demonstrar a existência de um Ser supremo, mas que terá sempre que deixar ao
argumento ontológico (ao qual serve somente de introduçáo), a tarefa de preencher esta
lacuna, contendo, portanto, este último argumento o único fundamento de prova possível
(na medida em que pode haver uma prova especulativa) que nenhuma razáo humana
poderia evitar (KANT, 2001, A625/B653).

Dado que a prova ontológica é segundo Kant um argumento falho, então o argumento físico-teológico, que o necessita fundamentalmente em sua argumentaçáo, acaba por falhar também, uma vez que necessita do argumento para chegar às suas conclusôes.

Desse modo, Kant termina sua refutação das provas da existência de Deus propostas pela teologia racional e pela metafísica tradicional. No entanto, as conclusóes de Kant sobre a teologia

16 GRIER, 2007, p.19. 
e o pensamento sobre Deus não possuem apenas um aspecto negativo. Kant não rejeita somente a teologia especulativa, mas também o ateísmo especulativo que afirma a não-existência de Deus. Kant rejeita, também, aquele tipo de positivismo que considera a noção de Deus como impensável e indigna da razão. ${ }^{17}$

Uma vez que Deus pode ser pensado sem contradiçáo, mas não pode ser conhecido teoricamente, Kant afirmou que a única teologia racional possível, independente de todo e qualquer tipo de revelação, seria a teologia que se fundamenta em leis morais:

Afirmo, pois, que todas as tentativas de um uso apenas especulativo da razão com respeito à teologia são totalmente infrutíferas e, pela sua índole intrínseca, nulas e vãs; mas que os princípios do seu uso natural não conduzem, de modo algum, a qualquer teologia e que, por conseguinte, se não tomarmos como base as leis morais ou não nos servirmos delas como fio condutor, não poderá haver, em absoluto, uma teologia da razão (KANT, 2001, A637/B664).

Nesse sentido, Kant manteve-se fiel ao seu idealismo transcendental, pois limitou o conhecimento em geral à experiência possível e deixou espaço para a discussão sobre Deus para o âmbito prático da moral, temática que foi discutida em sua obra Crítica da Razão Prática.

\section{Conclusáo}

Um dos resultados mais significantes obtidos pela tese kantiana sobre o ser na Crítica da Razão é a refutação dos argumentos da teologia racional que tentavam, pela metafísica tradicional, provar a existência de Deus. Neste artigo foram tomados todos os argumentos classificados e criticados por Kant (o ontológico, o cosmológico e o físico-teológico) e analisada a argumentação que fundamenta a refutação de Kant. Concluiu-se que, para Kant, o erro do argumento ontológico era querer extrair a existência de Deus a partir de conceitos lógicos fazendo, assim, um uso errôneo do juízo existencial.

Como foi visto, para se afirmar a existência de algo, deve se ter como fundamento algo provindo da experiência, o que não acontece com os argumentos ontológicos. Em relação aos

HÖFFE, 2005, p.174. 
argumentos cosmológico e físico-teológico, percebeu-se que ambos possuem o argumento ontológico como fundamento de sua argumentação e, por este motivo, recairiam no mesmo erro: o uso incorreto do conceito de ser para afirmaçáo de existência.

Assim, com a profunda análise dos argumentos que fundamentam a refutaçáo kantianaaos argumentos ontológicos, torna-se nítido o caráter epistemológico empreendido por Kant na Crítica da Razão Pura, principalmente na importância dada ao objeto real (experiência) para a afirmação da existência de algo

Contudo, apesar de todo o impulso da Dialética Transcendental paracer ser dirigida a uma redução da razão pura, deve ser salientado o papel positivo que a razão especulativa desempenha para a atividade científica. Nesse sentido, Kant sugere que a razáo que nos levou ao erro metafísico (como a formulação das provas da existência de Deus) é também a origem de idéias e princípios necessários para o conhecimento, como o princípio da unidade e da completude, que possibilitam o contínuo progresso da ciência em suas teses. 


\section{REFERÊNCIAS}

ARISTÓTELES. Metafísica: ensaio introdutório, texto grego com tradução e comentário de Giovanni Reale. São Paulo: Loyola, 2001-2002.

DESCARTES, René. Discurso do metodo; Meditações ; Objeções e respostas ; As paixóes da alma ; Cartas. 3a ed. - São Paulo: Abril Cultural, 1983.

GRIER, Michelle. Kant's Critique of Metaphysics. The Stanford Encyclopedia of Philosophy, Edward N. Zalta (ed.). Summer Edition, 2007. Disponível em <http://plato.stanford.edu/archives/sum2009/entries/kant-metaphysics/>. Acesso em: nov. 2010.

HÖFFE, Otfried. Immanuel Kant. São Paulo: Martins Fontes, 2005

KANT, Immanuel. Crítica da Razão Pura. 5.ed. Lisboa : Fundação Calouste Gulbekian, 2001. . The only possible argument in support of a demonstration of the existence of God. In: WALFORD, David; MEERBOTE, Ralf (Editores) Immanuel Kant - Theoretical Philosophy, 1755-1770. Cambridge: Cambridge University Press, 1992.

PASCAL, Georges. O pensamento de Kant. Trad.: Raimundo Vier. Petrópolis : Editora Vozes, 1983.

PLATÃO. As leis: incluindo Epinomis. São Paulo: EDIPRO, 1999.

REICHENBACH, Bruce. Cosmological Argument. The Stanford Encyclopedia of Philosophy. Edward N. Zalta (ed.). Winter Edition, 2008 Disponível em <http://plato.stanford.edu/archives/win2010/entries/cosmological-argument/>. Acesso em: nov. 2010.

SMITH, Plínio Junqueira. Dez provas da existência de Deus. São Paulo: Alameda, 2006. 
TOMATIS, Francesco. O argumento ontológico. : a existência de Deus de Anselmo a Shelling. Tradução: Sérgio José Schiarato - São Paulo : Paulus, 2003

VAZ, Bruno R. L. A recepção de Frege da noção kantiana de existência. Dissertação (Mestrado em Filosofia) - Programa de Pós-Graduação em Filosofia, Universidade Federal de Santa Maria, Santa Maria, 2006. 